\title{
THE OBSERVATION OF THE TRIPLET LEVELS OF CLOSED-SHELL TETROXO-COMPLEXES BY LUMINESCENCE MEASUREMENTS
}

\author{
G. BLASSE \\ Phy sical Laboratory. State Unis ersity. 3508 TA Litrecht. The -Netherlands
}

Received 21 February 1979

In vanadates and potassium dichromate the triplet levels have been observed by luminescence measurements. The energy- level schemes are in good agreement with each other and with calculated results.

A considerable amount of experimental and theoretical work has been performed to determine the electronic energy level diagram of tetrahedral closedshell tetroxo-transition-metal complexes. A recent survey has been given by Ronde [1]. The outstanding example in this group of compleses is the $\mathrm{MnO}_{4}^{-}$ion. but many isoelectronic complexes exist. It is generally agreed that the four lowest excited levels should be ${ }^{1} \mathrm{~T}_{2}>{ }^{1} \mathrm{~T}_{1}>{ }^{3} \mathrm{~T}_{1} \approx{ }^{3} \mathrm{~T}_{2}[2]$. Up till now the triplet levels have not been observed unambiguously in absorption due to their low absoiption strength and broad-band character. A study of the enission and excitation spectra of luminescence would be a considerably more sensitive technique. Unfortunately no luminescence has been reported for the $\mathrm{MnO}_{4}^{-}$ group.

A study of the luminescence of the vanadate group $\left(\mathrm{VO}_{4}^{3-}\right)$ has given strong evidence that the level sequence is ${ }^{1} \mathrm{~T}_{2}>{ }^{1} \mathrm{~T}_{1}>^{3} \mathrm{~T}_{2}>^{3} \mathrm{~T}_{1}$ and that the emission originates from the triplet levels [3]. The energy difference between the singlet levels was found to be $4000 \mathrm{~cm}^{-1}$, that between the triplet levels was estimated to be a few hundred wavenumbers.

Recently potassium dichromate $\left(\mathrm{K}_{2} \mathrm{Cr}_{2} \mathrm{O}_{7}\right)$ has been shown to luminesce below $30 \mathrm{~K}[4]$. Its emission, absorption and excitation spectra were reported. but no discussion of the origin of the energy level scheme was given. It is the purpose of this letter to compare the results and the interpretation of the experimental work on the $\mathrm{VO}_{4}^{3-}$ and the $\mathrm{Cr}_{2} \mathrm{O}_{7}^{2-}$ group and the calculated results in the literature.
An approximation we are forced to make is that we interpret the observed spectra of the $\mathrm{Cr}_{2} \mathrm{O}_{7}^{2-}$ group using the energy level structure of the tretrahedral $\mathrm{CrO}_{4}^{2-}$ group. This. howeser, has been done by several authors and seems to work [5]. Freibery and Rebane [4] report three absorption and excitation bands for the dicliromate group. Their electronic origin (zero-phonon line) at $4.2 \mathrm{~K}$ is reported at $563.5 \mathrm{~nm}$ (an extremely weak band system with $h \approx 0.1 \mathrm{~cm}^{-1}$ ), $550.3 \mathrm{~nm}$ (roughly 50 times more intense). $535.0 \mathrm{~nm}$ (again considerably more intense). From the literature data $[5,6]$ the origin of the strong absorption band in the blue is estimated to be at about $430 \mathrm{~nm}$. Luminescence was observed from the level with the $563.5 \mathrm{~nm}$ zero-phonon line, but also from that with the $535.0 \mathrm{~nm}$ zero-phonon line.

Following the assignment for the vanadate case we come to the following proposal: $5635 \mathrm{~nm}\left({ }^{3} \mathrm{~T}_{1}\right)$. $550.3 \mathrm{~nm}\left({ }^{3} \mathrm{~T}_{2}\right) .535 .0 \mathrm{~nm}\left({ }^{1} \mathrm{~T}_{1}\right) .430 \mathrm{~nm}\left({ }^{1} \mathrm{~T}_{2}\right)$. This assignment is in accordance with the intensities observed. Note that the energy difference between the singlets (about $4500 \mathrm{~cm}^{-1}$ ) agrees very well with that reported for the vandate group and with the value calculated by Ziegler et al. (about $4000 \mathrm{~cm}^{-1}$ ) [7] Also the energy- difference between the triplets (some $300 \mathrm{~cm}^{-1}$ ) agrees with that observed for the vanadate group. In agreement with prediction it is much smaller than for the singlets [2].

Ziegler et al. [8] have calculated the dverdged position of the singlets and the triplets. Their energy difference for the $\mathrm{CrO}_{4}^{2-}$ group was found to be 
$2100 \mathrm{~cm}^{-1}$. From the experimental data we find for this difference about $3000 \mathrm{~cm}^{-1}$. This is considered to be a reasonable agreenent. The present results suggest that luminescence from the $\mathrm{CrO}_{4}^{2-}$ group should be observable in a suitable host lattice. Measurements on such a system will add considerably to our experimental knowledge of the triplet levels.

\section{References}

[1] II. Ronuc, Thesis, University of Utrecht (1977), availdble upon request.
[2] C.J. Balliausen, Theoret. Chim. Acta 1 (1963) 285.

[3] H. Ronde and G. Blasse, J. Inorg. Nucl. Chem. 40 (1978) 215.

[4] A. Freiberg and L.A. Rebane, I. Luminescence 18/19 (1979) 702 .

[5] B.V.R. Chow dari and Y. Ravi Sekhar, Chem. Phys. Letters 59 (1978) 311;

S. Radhakrishna and B.D. Sharma, J. Chem. Phys. 61 (1974) 3925.

[6] N.K. Bel'skii and Ch.K. Mukhtarov, Optika i Spektroskopiya 14 (1963) 78 .

[7] T. Ziegler, A. Rauk and EJ. Baerends, cited in ref. 3.

[8] T. Ziegler, A. Rauk and E.]. Baerends, Chem. Plyys. 16 (1976) 209 